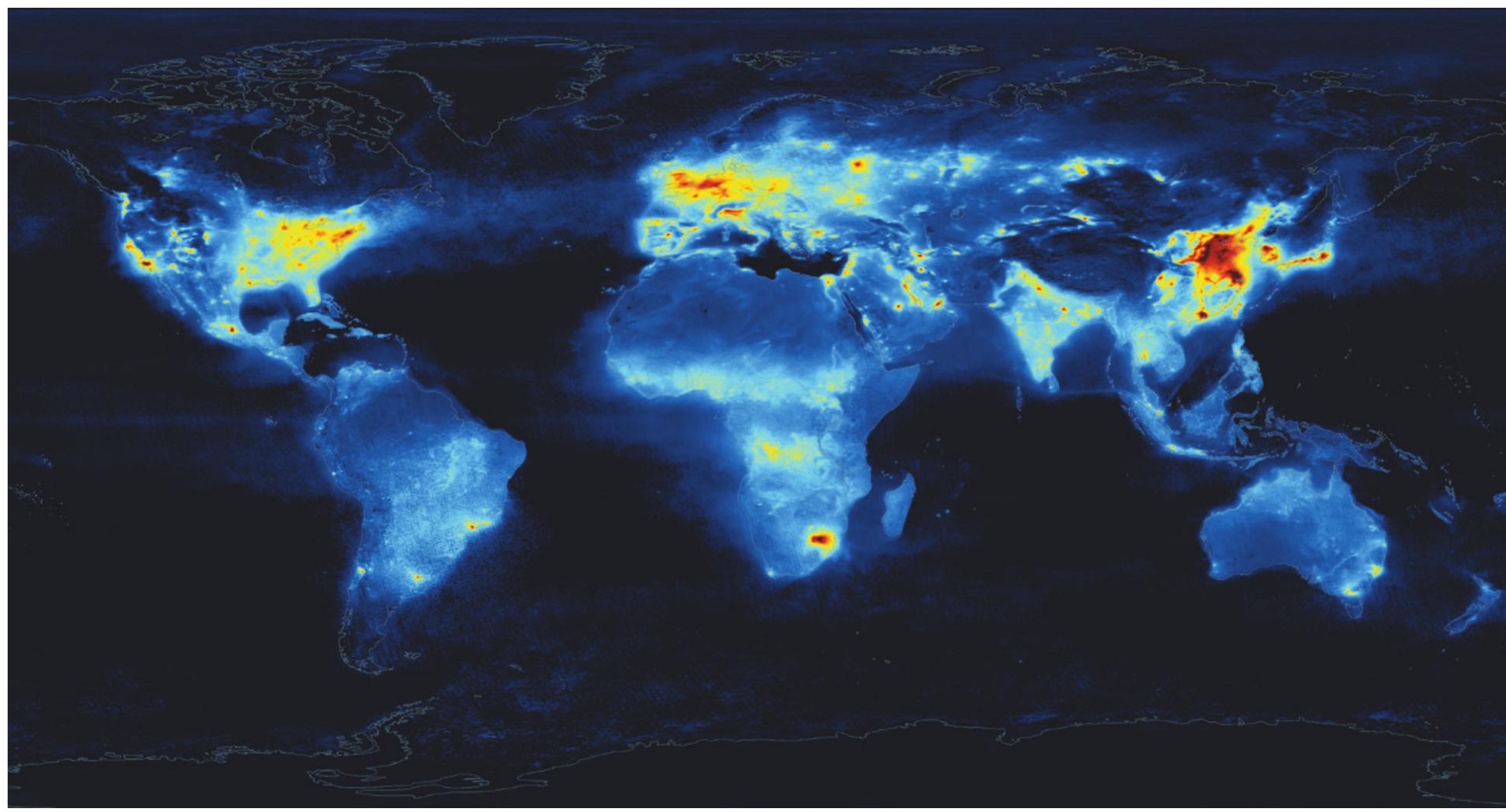

Global monitoring of atmospheric nitrogen dioxide reveals pollution hotspots.

\title{
Five priorities for the UN Sustainable Development Goals
}

\author{
Restructure data-gathering and evaluation networks to address climate change, \\ energy, food, health and water provision, say Yonglong Lu and colleagues.
}

\section{$\mathrm{T}$} his week, the United Nations is deliberating in New York how to implement the 17 Sustainable Development Goals (SDGs) that it will launch formally in September. Science must be at the heart of its plans.

The SDGs place greater demands on the scientific community than did the Millennium Development Goals (MDGs), which they replace ${ }^{1}$. Addressing climate change, renewable energy, food, health and water provision requires coordinated global monitoring and modelling of many factors - social, economic and environmental.

Much remains to be done: the 17 goals comprise 169 targets, 91 of which need to be specified in more detail. Metrics need to be developed to measure progress towards the targets on local, national, regional and global levels and across sectors. Monitoring and evaluation procedures and standards need to be set up.

To guide action, the connections between targets need to be better understood. Some synergies and trade-offs depend on scale — for instance, greater fertilizer use might increase food production and incomes locally, but would exacerbate pollution. Climate-change mitigation tends to happen at a local scale, but the consequences are global.

We lay out five priorities for how the scientific community should participate in this process, based on the findings of a scientific review ${ }^{1}$ of the draft SDGs conducted by the International Council for Science (ICSU).

\section{FIVE PRIORITIES}

Devise metrics. Scientists, social scientists and economists need to design a set of practical indices for tracking progress on each SDG. Ensuring access to sustainable and modern energy for all (goal 7), for example, will require indicators of improvements in energy efficiency and carbon savings from renewable-energy technologies (see go.nature.com/pkij7y). Parameters other than just economic growth must be included, such as income inequality, carbon emissions, population and lifespans ${ }^{1}$.

Existing methodologies can form the starting points, including environmental impact assessment, natural-asset valuation, cost-benefit analysis and life-cycle costing. Ambiguous terms in the wording of the goals, such as 'sustainable, 'efficient' and 'substantial', need to be defined quantitatively so that the goals can be measurable, comparable and achievable. Scientific analyses of the effectiveness of different scenarios should inform the metrics.

\section{Establish monitoring mechanisms.} Governments and researchers must decide which values need to be tracked, and set up systems to acquire the data. Quantities such as water and energy consumption, emissions and health impacts need to be monitored, as do scientific variables such as water $\mathrm{pH}$, turbidity and metal concentrations. Social scientists should propose what sorts of data on behaviour, values and beliefs should be collected and analysed, how and by whom ${ }^{1}$. 
Analysis and interpretation must be provided at the same time, ideally by an independent government-backed organization, to consider the data in context. In water-quality monitoring, for example, measurements of physical, chemical and biological features such as $\mathrm{pH}$ and chemical oxygen demand are compared against national or regional waterquality standards that relate to impacts on human and ecosystem health ${ }^{2}$.

Global collaboration between governments and scientific bodies will be essential in setting up monitoring programmes and in assisting developing nations to implement them ${ }^{3}$.

Evaluate progress. Scientists should help to choose criteria - such as the water-quality standards - against which progress towards the goals is judged, based on accepted principles of good practice or governance such as social equality or cost-effectiveness.

A peer-review mechanism should be established through the UN platform for intergovernmental negotiations to evaluate the performance and implementation of SDG projects and policies every $3-5$ years and suggest reforms where necessary.

The Intergovernmental Panel on Climate Change, the Intergovernmental Platform on Biodiversity and Ecosystem Services and other scientific-assessment bodies should set up task forces to decide how they can evaluate relevant aspects of the goals, either by extending their remits or by sharing their experiences with a central SDG assessment body ${ }^{3}$.

The SDG evaluators must also decide how to incorporate the contributions of regions, cities, companies and others into national and international pledges; consider national or local circumstances when evaluating progress; and check whether sustainable development has been incorporated into planning processes and strategies at all levels.

Enhance infrastructure. Earth observation, ground-based monitoring and informationprocessing capabilities need to be expanded to give better global coverage, to allow direct comparisons of data by using similar instruments, and to store, analyse and share data.

Much of this can be achieved if the SDG process engages with Future Earth, a tenyear initiative for global-sustainability research launched at the Rio+20 UN conference in 2012. Future Earth's observing networks, high-performance computing, Earth-system models, theoretical frameworks, data-management systems and research infrastructures need to be enhanced to track human dimensions and societal changes. The Science and Technology Alliance for Global Sustainability should help Future Earth to revise its agenda to include observations of production, consumption and urbanization.

The ICSU should work with international

bodies such as the World Meteorological Organization, the UN Educational, Scientific and Cultural Organization, and the UN Environment Programme to shape global monitoring networks to serve the SDGs. This will include changing the missions, objectives and targets of existing global observation systems, including those for climate, oceans and ecosystems.

Space-based monitoring coupled with on-the-ground observation is crucial for tracking changes on large scales - in natural-resource availability, landscape patterns and management, and social structure. Government investments need to be maintained or increased.

Data gathering using smart phones and miniature sen-

"Developing
countries
will need to
collaborate
with developed
countries to
build capacity."
sors can capture point-source industrial emissions, waste dumping and unsustainable consumption. Citizen science provides new opportunities. For example, starting in 2008, Beijing residents' use of Twitter to share air-pollution data obtained from home-based monitoring equipment pressured the municipality to improve its airquality monitoring. Such actions also serve as a check on reporting bias from governments, companies and others.

Geographical information systems will be needed to host and share data from the observing networks. Image processing, simulation and decision-making tools are also needed to support sustainability planning, management and enforcement. These should be openly accessible so that citizens can make informed decisions about, say, how to improve air quality or ocean health ${ }^{4}$. Businesses can track their environmental impacts and project future supplies ${ }^{5}$.

Developing countries will need to collaborate with developed countries to build capacity in observing, data mining and statistics $^{6}$. Bodies such as the G20 Development Working Group and the InterAcademy Panel should help with this.

Standardize and verify data. Countries' capabilities to acquire and process economic and social data vary greatly. The likelihood of collecting wrong or useless information is high, owing to a lack of standards and consistent methods and instrumentation. Scientists and governments need to design monitoring and sampling approaches with robustness in mind, and to verify data.

Cooperation among authorities and agencies is more effective if partners collect data according to agreed definitions, specifications, methodologies and formats. The Partnership in Statistics for Development in the 21st Century (PARIS21) aims to strengthen national statistical systems to monitor global goals, by promoting such shared principles ${ }^{3}$.

Checks must be made, for instance, by implementing complementary monitoring systems, comparing results from airborne and land-based surveillance or by inspecting data-collection methods. Shared online reporting platforms - perhaps modelled on the Google Earth Engine or the NASA Earth Exchange - should provide qualitycontrol services for data from different sources $^{7,8}$.

All SDG data must be open access and released as soon as possible. Governments, scientists and corporations will need to commit to long-term funding for the collection, calibration and release of data sets, which should be discussed in the SDG politicalnegotiation process. These commitments could then be checked at the high-level political forum held every year. Sanctions such as economic penalties will need to be considered for governments and companies that do not comply.

Scientists need to support the SDGs. We must help to integrate monitoring and evaluation mechanisms into policy-making at all levels and ensure that information about our planet is easily available to all.

Yonglong Lu is professor at the State Key Laboratory of Urban and Regional Ecology, Research Center for Eco-Environmental Sciences, Chinese Academy of Sciences, Beijing, China. Nebojsa Nakicenovic is deputy director-general of the International Institute for Applied Systems Analysis, Vienna, Austria. Martin Visbeck is professor at the GEOMAR Helmholtz Centre for Ocean Research and Kiel University, Germany. Anne-Sophie Stevance is a science officer at the International Council for Science, Paris, France.

e-mail:yllu@rcees.ac.cn

1. International Council for Science, International Social Science Council. Review of Targets for the Sustainable Development Goals: The Science Perspective (ICSU, 2015).

2. Australian and New Zealand Guidelines for Fresh and Marine Water Quality (Australian and New Zealand Environment and Conservation Council, Agriculture and Resource Management Council of Australia and New Zealand, 2000).

3. Organisation for Economic Co-operation and Development. Strengthening National Statistical Systems to Monitor Global Goals (OECD, 2013).

4. German Advisory Council on Global Change. World in Transition: Governing the Marine Heritage (WBGU, 2013).

5. European Environmental Agency. Shared Environmental Information System (SEIS) (EEA, 2011).

6. Saint Petersburg Development Outlook: Annex to the G20 Leaders' Declaration (G20, 2013).

7. United Nations Environment Programme. Embedding the Environment in Sustainable Development Goals (UNEP, 2013).

8. UN Independent Expert Advisory Group on the Data Revolution for Sustainable Development. A World That Counts: Mobilising the Data Revolution for Sustainable Development (UN IEAG, 2014). 